PLEASE NOTE:

This is the author's version of the manuscript accepted for publication in Journal of Reproductive and Infant Psychology. Changes resulting from the publishing process, namely editing, corrections, final formatting for printed or online publication, and other modifications resulting from quality control procedures, may have been subsequently added.

The published version can be found in: Santos, C., Sobral, M. P., \& Martins, M. V. (2017). Effects of life events on infertility diagnosis: Comparison with presumably fertile men and women. Journal of Reproductive and Infant Psychology, 35(1), 1-13. doi: 10.1080/02646838. 2016.1249834

Effects of life events on infertility diagnosis: comparison with presumably fertile men and women ${ }^{1}$

\author{
Carina Santos $^{1}$, Maria Pedro Sobral ${ }^{1,2}$, Mariana V. Martins, ${ }^{1,2, *}$ \\ ${ }^{1}$ University of Porto, Faculty of Psychology and Educational and Education Sciences \\ ${ }^{2}$ Center for Psychology at University of Porto \\ *correspondent author: Mariana V. Martins, PhD, Faculty of Psychology and \\ Education Sciences, University of Porto, 4200 Porto, Portugal. Phone. +351 226079 \\ 700; F.+351 226079 725, E-mail:mmartins@fpce.up.pt
}

Author information

Carina Santos, Master's Degree, Faculty of Psychology and Education Sciences, University of Porto, 4200 Porto, Portugal; R. Alfredo Allen, 4200-135 Porto, Portugal. Phone.+351 226079700; F. +351 226079725; carinamsantos92@gmail.com

Maria Pedro Sobral, PhD, Faculty of Psychology and Education Sciences, University of Porto, 4200 Porto, Portugal. Phone. +351 226079 700; F. +351 226079 725, E-mail: mpsobral@fpce.up.pt

Mariana V. Martins, PhD, Faculty of Psychology and Education Sciences, University of Porto, 4200 Porto, Portugal. Phone. +351 226079 700; F. +351 226079 725, E-mail: mmartins@fpce.up.pt

Funding: This work was supported by European Union Funds (FEDER/COMPETE Operational Competitiveness Programme) and by National Funds (FCT - Portuguese Foundation for Science and Technology) under the projects PTDC/MHC-PSC/4195/2012 and SHRH/BPD/85789/2012 


\begin{abstract}
Objective: To compare the occurrence and degree of stress attributed to life events during childhood/adolescence and adulthood between individuals diagnosed with infertility and presumably fertile individuals, and to examine the effect of life events occurrence and stress levels on an infertility diagnosis.

Background: Although stress has been very explored as a consequence of the experience of infertility, its role as a predictor of this disease still lacks research, particularly regarding the use of adequate control groups composed of nonparents.
\end{abstract}

Methods: The final sample had 151 infertile subjects ( 74 males and 77 females) and 225 presumably fertile participants (95 males and 130 females), who completed a questionnaire indicating occurrence $(\mathrm{y} / \mathrm{n})$ and degree of stress of life events (1-5) during childhood/adolescence and adulthood.

Results: Significant differences regarding occurrence were found in 7 stressful life events in men and in nine events in women, with infertile groups presenting higher occurrence than presumably fertile groups. Eleven stressful life events were rated differently by men and women regarding the degree of stress, with group significant differences observed in both directions. While most events were rated as more stressful by infertile men infertile women reported less stress resulting from these events than presumably fertile women. After controlling for age, the degree of stress induced by life events in childhood/adolescence and adulthood were not significant predictors of infertility diagnosis, for both men and women.

Conclusion: The amount of stress associated with earlier or concurrent life events does not seem to be related with infertility. Further prospective research is needed to validate these findings.

Keywords: life events, stress, infertility, infertility diagnosis, male infertility, female infertility 


\section{Effects of life events on infertility diagnosis: comparison with presumably fertile}

\section{men and women}

Infertility is diagnosed after at least 12 months of regular unprotected sexual intercourse without conceiving (WHO, 2009), and affects approximately 9\% of couples worldwide (Boivin, Bunting, Collins \& Nygren, 2007). Besides a reproductive system disease, infertility is also a biopsychosocial health problem in the sense that both causation and outcome are product of an interaction between biological, psychosocial and social factors (Leigh \& Reiser, 1980). Research has shown that experiencing infertility and its treatments can decrease quality of life (Fekkes et al., 2003; Lau, Wang, Kim, Yang \& Tsui, 2008; Onat \& Beji, 2012) and increase distress (Verhaak et al., 2007; Rostad, Schmidt, Sundby \& Schei , 2014). Indeed, couples report the experience of infertility as one of the most stressful events in their lives (Klonoff-Cohen, Chu, Natarajan \& Sieber, 2001).

Stress occurs when an event is perceived to exceed an individual's personal resources (Lazarus \& Folkman, 1984). While literature is extensive with respect to stress as a result of the infertility experience (see Gourounti, Anagnostopoulos, \& Vaslamatzis, 2010, for a review), little attention has been given to the role of stress as a predictor of infertility (Kamath \& Bhattacharya, 2012; Lynch, Sundaram, Maisog, Sweeney \& Louis , 2014). There is now evidence that the body's immune response can be suppressed by high levels of stress, which in turn increase the chance of infection and chronic health problems (NSCDC, 2015). Several studies have shown a link between stress during early life stages and adult health, including depression (Honkalampi et al., 2005), heart disease (Bomhof-Roordink et al., 2015; Dong et al., 2004), female breast cancer (Goldsmith et al., 2010), central arterial stiffness (Bomhof-Roordink et al., 2015), induction or 
exacerbation of psoriasis (Malhotra \& Mehta, 2008) and fibromyalgia (Anderberg, Marteinsdottir, Theorell \& Knorring, 2000).

Stress can also interfere with the reproductive function through an inhibitory effect on the hypothalamic-pituitary-gonadal axis (Warren and Fried, 2001), or even supress the reproductive function (e.g. amenorrhea) (Nakamura, Sheps \& Arck, 2008). However, research on the relationship between stress and assisted reproductive technology outcomes (i.e., pregnancy or conception rates resulting from treatment) has produced mixed findings, with evidence both in favor of and against this association (see reviews of Boivin, Griffiths, and Venetis, 2011; Morreale, Balon, Tancer, and Diamond, 2010).

These contradictory findings are in part due to how outcomes and stress are defined and assessed. Most studies focus on successful pregnancy after treatment as outcome (e.g., Boivin \& Schmidt, 2005; Boivin, Sanders and Schmidt, 2006), but reproductive impairment is already occurring for at least one year. Additionally, reported or measured stress levels might be high but not perceived as negatively influencing the individual (Ebbesen et al., 2009). In a recent study, Lynch and collaborators (2014) demonstrated that high stress levels can lead to a significant reduction in fecundity in women attempting to conceive.

While there is some indication that stress can affect the both female (e.g., Boivin \&

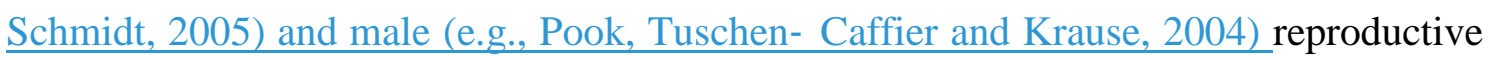
function, there are no studies focusing on the impact of stressful life events on infertility diagnosis. We propose to address this gap by exploring the links between childhood, adolescence and adulthood stressful life events (regarding both occurrence and degree of attributed stress) and male and female infertility. To do so, men and women seeking fertility treatments need to be compared against control groups of presumably fertile men and women (i.e., not aware of having any reproductive difficulty). Thus, this paper 
examines (i) whether there are differences between infertile and presumably fertile men and women in the way they experience stressful life events, regarding both occurrence and degree of attributed stress; and (ii) whether stressful life events can predict male and female infertility. Because parenthood is one of the most taxing transitions in an individual's life cycle (Rholes, Simpson, Campbell \& Grich, 2001), we cared for controlling this potential bias by including only married/cohabiting individuals with no children.

\section{Method}

\section{Participants}

Infertile(I) and presumably fertile(PF) groups were selected using different data collection methods. The I group included 389 infertile patients (203 women and 186 men) seeking treatment at a public fertility centre (detailed information provided elsewhere on Martins, 2012 and Martins, Peterson, Almeida, Mesquita-Guimarães and Costa, 2014). The Portuguese National Health Service partially reimburses infertility medication (69\% of the total cost), and provides free access to infertility first-line treatments for women $<42$ years of age, and second-line treatments for women $<40$ years. All ovulation induction treatments are financed, as well as up to three intrauterine insemination (IUI) cycles and three in vitro fertilization (IVF) or intracytoplasmatic injection (ICSI) cycles. Infertility diagnoses were obtained through medical records. In this study, only individuals with a fertility problem were included, i.e. infertility causation had to be determined and could not be attributed to the subject's partner or to an idiopathic cause $(n=212)$. We further excluded 13 participants who had children, seven whose diagnosis was related to paraplegia or tubal ligation, and six who did not complete the questionnaire. 
PF participants were recruited for this study through an online survey $(n=245)$. To participate, subjects had to: a) be married or cohabiting; b) have no children; and c) not knowing of any reproductive difficulty or fertility problem. Twenty participants were excluded for not completing the questionnaire.

The final sample had a total of 376 subjects, with 151 I (74 men and 77 women), and $225 \mathrm{PF}$ (95 men and 130 women).

\section{Procedure}

Infertile couples attending the fertility centre between February 2010 and March 2011 were invited by their physician to participate in the study at conclusion of their consult. Patients who agreed were given a study information sheet and signed a consent form, and completed self-report measures in a separate room. Ethical approval for this sample was obtained from the Portuguese Data Protection Authority and the Hospital Ethics Committee.

PF participants were invited to respond to an online survey via e-mail. Addresses were obtained through the Faculty of Psychology and Education Sciences alumni database and links were posted on the school website and social networks profiles between April 2014 and October 2014. As incentive, subjects entered a lottery to win a $100 €$ gift card. Consent was obtained from all participants. The present study was approved by the University of Porto Faculty of Psychology and Education Sciences Ethics Committee.

\section{Measures}

Socio-demographic variables were obtained using a specifically designed questionnaire that assessed age, marital status, cohabitation length, and parity. Infertility diagnosis was assessed via medical records. 
The Life Event Inventory (Anderberg, et al., 2000) assesses the number of life events an individual experiences throughout life. The questionnaire covers both childhood/adolescence (11 items; e.g., "conflict with parents") and adulthood (19 items; e.g., "severe disease or accident"). In this version, the subject was asked to rate the extent to which events were stressful if they had occurred, using a five-point Likert-scale $(1=$ "not stressful"; 5= "extremely stressful").

\section{Statistical Analyses}

Statistical analyses were performed using the Statistical Package for Social Sciences (SPSS, version 21). First, in order to check for possible confounders, statistical comparisons were conducted with socio-demographic variables using independent samples T-tests. Variables revealing to be significantly different between I and PF groups were then analysed for association with occurrence of life events and attributed degree of stress using Spearman's and Pearson correlation coefficients, respectively.

To analyse differences between I and PF subjects in the occurrence of life events, cross-tabulation analyses using the Chi-square test (Exact method) were performed. Differences concerning the level of stress attributed were analysed using independent samples T-tests.

The influence of stress attributed to life events on the diagnosis of infertility was tested using multiple logistic regressions analyses. Given that age is expected to have a significant role in both male and female infertility diagnosis (Belloc, Hazout, Zini, Merviel, Cabry, Chahine, Copin \& Benkhalifa,, 2014; Bretherick, Fairbrother, Avila, Harbord \& Robinson,, 2010), we controlled for age in both models (step 1). Mean degree of stress attributed to both childhood/adolescence and adulthood life events were entered as independent variables in step 2. All analyses were performed separately for men and women. 


\section{Results}

\section{Descriptive results}

Average age was 30.52 years $(S D=5.979)$ for PF subjects and $33.08(S D=5.104)$ for I subjects. I subjects were significantly older than PF subjects $\left(t_{(352,028)}=4.438, p<\right.$ $.001)$. Infertile subjects had been living together for an average of 6.33 years $(S D=$ 3.474) and PF participants for 4.14 years $(S D=4.22)\left(t_{(374)}=5.288, p<.001\right)$. Because these significant differences were observed between groups, we analysed the association between these variables and the occurrence of life events and attributed stress before proceeding (data not shown). Regarding the occurrence of stressful life events, age and cohabitation length were positively associated with sexual assault in childhood/adolescence and adulthood, death of a parent in childhood/adolescence and adulthood, and a serious disease or accident affecting the individual or someone close during adulthood. Cohabitation length was also positively associated with the occurrence of problems with the partner's family. As for the experienced stress associated with the occurrence of life events, both age and cohabitation length were positively correlated with the stress inherent to the death of a parent in childhood/adolescence and adulthood. Age was positively associated to sexual assault in adulthood stress, and to the stress of having a serious disease or accident experienced by the self or someone close in adulthood, but negatively correlated with stress in a conflict with someone close. Bullying in childhood/adolescence was negatively associated to cohabitation length.

Table 1 depicts results concerning the occurrence of life events for I and PF subjects and respective impact. Statistics are presented separately for male and female subjects. On average, participants reported a mean number of $4.78(S D=2.74$; range $0-11)$ stressful life events during childhood/adolescence, and 9.65 ( $S D=4.81$; range $0-19)$ during 
adulthood, with a mean degree of stress of $3.91(S D=1.08)$ in childhood/adolescence, and of $4.05(S D=1.21)$ in adulthood.

Significant differences regarding occurrence were only found in eight life events out of 31 in both male and female groups. While higher occurrences were reported by I individuals in the male group (viz., negligence during childhood/adolescence; sexual assault, serious disease or accident of someone close, and death of a parent both during childhood/adolescence and adulthood; and physical or psychological abuse during adulthood), in the female group differences were observed in both directions, with five events occurring more frequently for PF women (death of someone close and bullying during childhood/adolescence; conflict with partner, conflict with someone close, and support to someone close during adulthood) and three significantly more reported by I women (death of a parent both during childhood/adolescence and adulthood, and serious disease or accident during adulthood).

As for the degree of stress attributed to life events, significant results were observed in 11 events for men and in 14 events for women. I men reported significantly higher stress in 6 events (negligence during childhood/adolescence; and physical or psychological abuse, serious disease or accident, death of a parent, bullying, and sexual difficulties during adulthood), and lower stress in 5 comparing to PF men (support to someone close both during childhood/adolescence and adulthood; and lack of control of work situation, financial problems, change of employment status during adulthood) . In the female group, I women exhibited significantly higher stress levels in only 2 events (sexual assault and death of a parent during adulthood), and significantly lower stress in 13 events (conflict with parents and support someone close during childhood/adolescence; physical or psychological abuse and bullying both during childhood/adolescence and adulthood; and conflict with partner, lack of control of work 
situation, financial problems, change of employment status, partners' change of employment status, sexual difficulties, and problems with family during adulthood).

\section{Effects of stress attributed to life events on infertility diagnosis}

Table 2 presents the regression coefficients, odds ratio (OR) and 95\% confidence intervals (CI) for infertility by age, degree of stress related to life events during childhood/adolescence, and degree of stress related to life events during adulthood, for men and women separately.

For males, the final model containing all predictors was statistically significant $\left(\chi^{2}\right.$ (3) $=10.722, p=.013)$. The model as a whole explained between $6.2 \%\left(\right.$ Cox and Snell $\left.R^{2}\right)$ and $8.3 \%$ (Nagelkerke $R^{2}$ ) of the variance in infertility diagnosis, and correctly classified $59.5 \%$ of cases. Only age predicted male infertility, with results indicating that each additional year increased the risk of male infertility by a factor of 0.092 (95\% CI 1.032$1.165)$.

For females, the final model was also significant $\left(\chi^{2}{ }_{(3)}=25.620, p<.001\right)$, explaining between $11.6 \%\left(\right.$ Cox and Snell $R^{2}$ ) and $15.9 \%\left(\right.$ Nagelkerke $\left.R^{2}\right)$ of the variance. The model correctly classified $68.6 \%$ of cases. Similarly to the male model, only age increased the likelihood of a female infertility diagnosis $(\mathrm{OR}=.089$ and $95 \% C I=1.033-1.156)$.

\section{Discussion}

The purpose of this study was two-fold: (i) to test whether infertile subjects report more occurrence and higher stress levels in life events than presumably fertile subjects; and (ii) to test whether the amount of stress attributed to life events during childhood/adolescence and adulthood predicts an infertility diagnosis. Not only was this the first study to focus on the impact of stressful life events on infertility diagnosis, but also the first to compare a group of infertile subjects with a cause attributed to themselves to a group of childless presumably fertile individuals. In general, results from this study 
showed that there is no evidence supporting the hypothesis that infertile individuals might have suffered a higher number of stressful events than fertile individuals or that the stress caused by these events can influence an infertility diagnosis. Our results support Whischmann's (2003) point of view against the assumption of a "psychological

\section{blockade" in connection with infertility.}

When taking gender into account, results concerning both the occurrence and the degree of stress attributed to life events support this lack of association. Similarities between men and women results regarding the frequency of events were only found in the death of a parent both during childhood/adolescence and adulthood and sexual assault during adulthood, with both I women and I men reporting a larger frequency than PF groups. Age was also positively associated with the occurrence of these particular events. While these associations could help explain these findings, given that I groups were significantly older than PF groups, the interval is only of 2,5 years. There were also variables in which the differences found were in opposite directions according to gender. For instance, I men reported sexual difficulties as more stressful than PF men, but I women reported less stress than PF women. This result is in accordance with previous evidence showing that infertile men report a higher prevalence of sexual dysfunction and infertile women report higher levels of desire (Monga, Alexandrescu, Katz, Stein \& Ganiats, 2004) due to the pressure of procreative sex and compliance with the calendar (fertile window) by initiative of the female partner. Finally, while I women were more stressed from physical or psychological abuse and bullying than PF women, the opposite was verified in the men groups. Considering that participants rated these experiences while going through the experience of infertility, we can speculate that infertile subjects might relate these events with the fertility problem itself. For example, women disclose infertility to more people and suffer higher stigma than men (Slade, O’Neill, Simpson \& 
Lashen, 2007), and hence would classify these events as bullying and psychological abuse. Another speculative hypothesis is interpreting daily injections and invasive examinations that are part of treatment as physical abuse.

On the other hand, as facing infertility is one of the most distressing challenges a couple can experience (Greil, Slauson-Blevins, \& McQuillan, 2010), one has to consider the possibility that stress related to past events may not be as burdensome as the current event subjects are going through, i.e., the experience of infertility. Having to cope with infertility might generate lower stress ratings in events such as lack of control of work situation, financial problems, or change of employment. This seems to be particularly true for women, as findings revealed a clear tendency for PF women to rate life events during adulthood as more stressful than I women.

Both male and female regression analyses showed that the effect of stress levels attributed to life events during childhood/adolescence and adulthood was not significant in the infertility diagnosis. As expected, age had a significant effect on infertility in both genders. This result is consistent with previous evidence indicating age as the main risk factor for female infertility (especially from age 35 and up; Bretherick et al. 2010; Madankumar, Cohen, \& Brenner, 2003), and a significant risk for male infertility (particularly for men older than 45; Stewart \& Kim, 2011; Kimberly et al., 2012; Varshini, Srinag, Kalthur, Kumar, Rao \& Adiga , 2012).

An additional explanation for the lack of significance between stressful live events and diagnosed infertility is the fact that individuals may already be engaged in psychological strategies to cope with their past negative life events. In other words, in order to cope and/or adjust to emotional hard events, participants may have used selfregulation strategies such as reappraisal, suppression, or cognitive dissonance-reduction through-out life - and the use of such strategies may have buffered the reported stress 
levels. Additionally, the level of stress associated with past life events may not be remembered with the real veracity (Smith, et al, 1999). Finally, the stress related to life events can have a different duration in time, thus having different impacts on the reproductive system. Knowing that different stressful stimulus can lead to different types of stress (chronic or acute), we may expect them to interfere with the reproductive system differently (Lynch et al., 2014).

Although groundbreaking in its aims, this study presents some limitations. One possible weakness lies in the sample size and low power to test the null hypothesis, as our absence of evidence does not necessarily means that there is evidence of absence of difference between the two groups (Altman \& Bland, 1995). Second, the retrospective nature of psychosocial data can implicate cognitive or emotional bias, particularly when it refers to events during childhood. Furthermore, results could have been skewed by the emotional state of infertile subjects at the moment of assessment. The fact that these individuals were experiencing the demanding experience of infertility at that time can have led them to devalue past life events, particularly the ones occurred during adulthood. Future studies can investigate if infertility distress levels are associated with the amount of distress recalled from former events. Furthermore, prospective studies encompassing the stressful life events that individuals experience throughout the life span would be needed in order to determine the impact of such events in infertility more accurately. Third, information about the specific pathologies behind the infertility diagnosis of each participant was limited. By excluding the individuals with pre-existing reasons for fertility problems (namely, paraplegia and tubal ligation), we were able to examine the association between stress and natural non-conception solely (whatever the biological problem under the infertility diagnosis was). However, the diagnosis of infertility may reflect a significant amount of specific reproductive problems, such as hypogonadotropic 
hypogonadism (Wiser, Sandlow \& Köhler, 2012) in men, or endometriosis (Asmaeilzadeh, Mirabi, Basirat, Zeinalzadeh \& Khafri, 2015), chronic pelvic inflammatory or failure of ovulation in women (Abarikwu, 2013). In other words, this study did not distinguish among the various pathologies referenced in infertility diagnosis with female and male factor, as it is possible that, for example, stress affects infertility via chronic pelvic inflammatory disease, but not tubal obstruction. Additionally, although all PF participants reported not knowing of any reproductive difficulty or fertility problem, the lack of a fertility problem was not medically confirmed, and some could have been trying to conceive for a long period and hence suspect that one of the partners or both member might have infertility. Finally, the fact that age and cohabitation length were associated with occurrence and stress of some life events requires us to carefully interpret results. Other variables related to the life-span may influence the relationship between life events and diagnosis of infertility. For example, the fact that cohabitation length was negatively associated with the stress induced by death of a parent suggests a buffer effect of the significant romantic relationship in the individual's levels of stress related to the life event.

Further studies should explore potential protective factors regarding the impact of stressful life events in infertility. Although this study shows no evidence that the stress attributed to a number of life events throughout the life span can have an impact on male or female infertility, the retrospective nature of this study prevents us to firmly conclude the lack of influence of stress related to life events in infertility. Additional research is needed, focusing in both intensity and duration of the stress induced by life events and its impact on different causations of male and female infertility. 


\section{References}

Abarikwu, S. O. (2013). Causes and risk factors for male-factor infertility in Nigeria: a review. African Journal of Reproductive Health, 17(4), 150-166.

Altman, D. G., \& Bland, J. M. (1995). Statistics notes: Absence of evidence is not evidence of absence. BMJ, 311(7003), 485 .

Anderberg, U., Marteinsdottir, I., Theorell, T., \& Knorring, L. (2000). The impact of life events in female patients with fibromyalgia and in female healthy controls. Elsevier 15, 295-301.

Asmaeilzadeh, S., Mirabi, P., Basirat, Z., Zeinalzadeh, M. \& Khafri S. (2015). Association between endometriosis and hyperprolactinemia in infertile women. Iranian Journal of Reproductive Medicine, 13(3), 155-160.

Bartlam, B. \& Woolfe, R. (1998). Working with survivors of child sexual abuse within the context of infertility. The European Journal of Psychotherapy, Counselling \& Health, 2, 183-193.

Belloc, S., Hazout, A., Zini, A., Merviel, P., Cabry, R., Chahine, H., Copin, H. \& Benkhalifa, M. (2014). How to overcome male infertility after 40: influence of paternal age on fertility. Elsevier, 78, 22-29.

Boivin, J., \& Schmidt, L. (2005). Infertility-related stress in men and women predicts treatment outcome 1 year later. Fertility and sterility, 83(6), 1745-1752.

Boivin, J., Bunting, L., Collins, J. A., \& Nygren, K. G. (2007). International estimates of infertility prevalence and treatment-seeking: Potential need and demand for infertility medical care. Human Reproduction, 22, 1506-1512. doi: 10.1093/humrep/dem046

Boivin, J., Griffiths, E., \& Venetis, C. A. (2011). Emotional distress in infertile women and failure of assisted reproductive technologies: meta-analysis of prospective psychosocial studies. $B M J, 342, \mathrm{~d} 223$.

Boivin, J., Sanders, K., \& Schmidt, L. (2006). Age and social position moderate the effect of stress on fertility. Evolution and human behavior, 27(5), 345-356.

Bomhof-Roordink, H., Seldenrijk, A., Hout, H. P. J., Marwijk, H. W. J., Diamant, M. \& Penninx, B. W. J. (2015). Associations between life stress and subclinical cardiovascular disease are partly mediated by depressive and anxiety symptoms. Journal of Psychosomatic Research, 78, 332-339. Elsevier. 
Bretherick, K. L., Fairbrother, N., Avila, L., Harbord, S. H. \& Robinson, W. P. (2010). Fertility and aging: do reproductive-aged Canadian women know what they need to know? Fertility \& Sterility, 93(7), 2162-2168.

Culley, L., Hudson, N., \& Lohan, M. (2013). Where are all the men? The marginalization of men in social scientific research on infertility. Reproductive biomedicine online, 27(3), 225-235.

Dong, M., Giles, W. H., Felitti, V. J., Dube, S. R., Williams, J. E., Chapman, D. P. \& Anda, R. F. (2004). Insights into causal pathways for ischemic heart disease: adverse childhood experiences study. Circulation. 13, 1761-1766.

Ebbesen, S. M. S., Zachariae, R., Mehlsen, M. Y., Thomsen, D., Hojgaard, A., Ottosen, L., Petersen, T. \& Ingerslev, H. J. (2009). Stressful life events are associated with a poor in-vitro fertilization (IVF) outcome: a prospective study. Human Reproduction, 9, 2173-2182.

Fekkes, M., Buitendijk, S. E., Verrips, G. H. W., Braat, D. D. M., Brewaeys, A. M. A., Dolfing, J. G., Kortman, M., Leerentveld, R. A. \& Macklon, N. S. (2003). Healthrelated quality of life in relation to gender and age in couples planning IVF treatment. Human Reproduction, 7, 1536-1543.

Goldsmith, R. E., Jandorf, L., Valdimarsdottir, H., Amend, K. L., Stoudt, B. G., Rini, C., ... \& Bovbjerg, D. H. (2010). Traumatic stress symptoms and breast cancer: The role of childhood abuse. Child abuse \& neglect, 34(6), 465-470.

Gourounti, K., Anagnostopoulos, F. \& Vaslamatzis, G. (2010). Primary appraisal of infertility: evaluation of the psychometric properties of a Greek version of the Appraisal of Life Events scale (ALE) in a Sample of infertile women undergoing fertility treatment. Women Health, 50(7), 688-704.

Greil, A. L., Slauson-Blevins, K., \& McQuillan, J. (2010). The experience of infertility: a review of recent literature. Sociology of Health \& Illness, 32(1), 140-162.

Honkalampi, K., Honkalampi, K., Hintikka, J., Haatainen, K., Koivumaa-Honkanen, H., Tanskanen, A., \& Viinamäki, H. (2005). Adverse childhood experiences, stressful life events or demographic factors: which are important in women's depression? A 2-year follow-up population study. Australian and New Zealand Journal of Psychiatry, 39(7), 627-632. 
Inhorn, M. C., \& Patrizio, P. (2015). Infertility around the globe: new thinking on gender, reproductive technologies and global movements in the 21st century. Human reproduction update, dmv016.

Jewkes, R. (2002). Intimate partner violence: causes and prevention. Violence against women III, 359, 1423-1429.

Jewkes, R., Levin, J. \& Penn-Kekana, L. (2002). Risk factors for domestic violence: findings from a South African cross-sectional study. Social Science and Medicine, 55(9), 1603-1617.

Kamath, M. S. \& Bhattacharya, S. (2012). Demographics of infertility and management of unexplained infertility. Best Practice \& Research Clinical Obstetrics \& Gynaecology, 26(6), 729-738.

Kimberly, L., Case, A., Cheung, A. P., Sierra, S., AlAsiri, S., Carranza-Mamane, B., Case, A., Dwyer, C., Graham, J., Havelock, J., Hemmings, R., Lee, F., Liu, K., Murdock, W., Senikas, V., Vause, T. D. \& Wong, B. C. (2012). Advanced reproductive age and fertility: no. 269, November 2011. International journal of gynaecology and obstetrics: the official organ of the International Federation of Gynaecology and Obstetrics, 117(1), 95-102.

Kissi, Y., Romdhane, A., Hidar, S., Bannour, S., Idrissi, K., Khairi, H., \& Ali, B. (2013). General psychopathology, anxiety, depression and self-esteem in couples undergoing infertility treatment: a comparative study between men and women. European Journal of Obstetrics \& Gynecology and Reproductive Biology, 167, 185-189.

Klonoff-Cohen, H., Chu, E., Natarajan, L. \& Sieber, W. (2001). A prospective study of stress among women undergoing in vitro fertilization or gamete intrafallopian transfer. Fertility \& Sterility, 76, 675-687.

Lau, J. T. F., Wang, Q., Kim, J. H., Yang, X. \& Tsui, H. Y. (2008). Infertility-related perceptions and responses and their associations with quality of life among rural Chinese infertile couples. Journal of Sex \& marital Therapy, 34, 248-267. Routledge.

Lazarus, R. S., \& Folkman, S. (1984). Stress, appraisal, and coping. Springer publishing company. 
Leigh H., Reiser M.F.(1980). The patient. Biological, psychological and social dimension of medical practice. New York: Plenum Press.

Lynch, D. C., Sundaram, R., Maisog, M. J., Sweeney, M. A. \& Louis, B. M. G. (2014). Preconception stress increases the risk of infertility: results from a couple-based prospective cohort study - the LIFE study. Human Reproduction, 29(5), 10671075.

Madankumar, R., Cohen, M. A., \& Brenner, S. H. (2003). Age and fertility. Primary care update for ob/gyns, 10(6), 270-273.

Malhotra, S. K. \& Mehta, V. (2008).Role of stressful life events in induction or exacerbation of psoriasis and chronic urticarial. Indian Journal of Dermatology, Venereology and Leprology, 74(6), 594-599.

Martins, M.V.. 2012. "Social Support, coping and depression in men and women facing infertility: examining mediating, moderating and dyadic effects". University of Porto: $\mathrm{PhD}$ dissertation defended.

Martins, M. V., Peterson, B. D., Almeida, V., Mesquita-Guimarães, J., \& Costa, M. E. (2014). Dyadic dynamics of perceived social support in couples facing infertility. Human Reproduction, 29(1), 83-89.

Middlebrooks, J. S. \& Audage, N. C. (2008). The effects of childhood stress on health across the lifespan. National Center for injury prevention and control.1-16.

Monga, M., Alexandrescu, B., Katz, S. E., Stein, M. \& Ganiats, T. (2004). Impact of infertility on quality of life, marital adjustment, and sexual function. Urology, 63, 126-130.

Morreale, M., Balon, R., Tancer, M., \& Diamond, M. (2010). The impact of stress and psychosocial interventions on assisted reproductive technology outcome. Journal of Sex \& Marital Therapy, 37(1), 56-69.

Nakamura, K., Sheps, S., \& Arck, P. C. (2008). Stress and reproductive failure: past notions, present insights and future directions. Journal of Assisted Reproduction and Genetics, 25(2-3), 47-62.

NSCDC: National Scientific Council on the Developing Child (2015). Supportive Relationships and Active Skill-Building Strengthen the Foundations of Resilience: Working $\quad$ Paper 13 Retrieved from: 
file://C:/Users/mpsobral/Downloads/Working\%20Paper\%2013\%20\%20Resilience.pdf

Onat, G., \&Beji, N. (2012). Effects of infertility on gender differences in marital relationship and quality of life: a case-control study of Turkish couples. European Journal of Obstetrics \& Gynecology and Reproductive Biology, 165, 243-248.

Peterson, B. D., Pirritano, M., Block, J. M., \& Schmidt, L. (2011). Marital benefit and coping strategies in men and women undergoing unsuccessful fertility treatments over a 5-year period. Fertility and Sterility, 95(5), 1759-1763

Pook, M., Tuschen-Caffier, B., \& Krause, W. (2004). Is infertility a risk factor for impaired male fertility?. Human Reproduction, 19(4), 954-959.

Rholes W. S., Simpson J. A., Campbell L., Grich J. (2001). Adult attachment and the transition to parenthood. Journal of Personality and Social Psychology, 81.

Rostad, B., Schmidt, L., Sundby, J. \& Schei, B. (2014). Infertility experience and health differentials - a population-based comparative study on Infertile and non-infertile women (the HUNT Study), Acta Obstetricia et Gynecologica Scandinavica, 93, 757-764.

Schmidt, L., Holstein, B., Christensen, U. \& Boivin, J. (2005). Does infertility cause marital benefit? An epidemiological study of 2250 women and men in fertility treatment. Patient Education and Counseling, 59(3), 244-251.

Slade, P., O'Neill, C., Simpson, A. J., \& Lashen, H. (2007). The relationship between perceived stigma, disclosure patterns, support and distress in new attendees at an infertility clinic. Human Reproduction, 22(8), 2309-2317.

Smith, R. E., Leffingwell, T. R., \& Ptacek, J. T. (1999). Can people remember how they coped? Factors associated with discordance between same-day and retrospective reports. Journal of Personality and Social Psychology, 76(6), 1050-1061.

Stewart, A. F., \& Kim, E. D. (2011). Fertility concerns for the aging male. Urology, 78(3), 496-499.

Straus, M. A., Gelles, R. J. \& Steinmetz, S. K. (2006). Behind Closed Doors: Violence in the American Family. Retrieved from http://pubpages.unh.edu/ mas2/Behind\%20Closed\%20Doors\%20-\%20newintro-06-Web.pdf 
Sydsjõ, G., Ekholm, K., Wadsby, M., Kjellberg, S., Sydsjõ, A. (2005). Relationships in couples after failed IVF treatment: a prospective follow-up study. Human Reproduction, 20, 1952-1957.

Varshini, J., Srinag, B. S., Kalthur, G., Krishnamurthy, H., Kumar, P., Rao, S. S., \& Adiga, S. K. (2012). Poor sperm quality and advancing age are associated with increased sperm DNA damage in infertile men. Andrologia, 44(s1), 642-649.

Verhaak, C. M., Smeenk, J. M., Evers, A. W., Kremer, J. A., Kraaimaat, F. W. \& Braat, D. D. (2007). Women's emotional adjustment to IVF: a systematic review of 25 years of research. Human Reproduction Update, 13(1), 27-36.

Warren, M. P., \& Fried, J. L. (2001).Hypothalamic amenorrhea. The effects of environmental stresses on the reproductive system: a central effect of the central nervous system. Endocrinology and Metabolism Clinics of North America, 30, 611-29.

Wischmann, T. H. (2003). Psychogenic infertility - myths and facts. Journal of assisted reproduction and genetics, 20(12), 485-494.

Wischmann, T., \& Thorn, P. (2013). (Male) infertility: what does it mean to men? New evidence from quantitative and qualitative studies. Reproductive biomedicine online, 27(3), 236-243.

Wiser, H. J., Sandlow, J., \& Köhler, T. S. (2012). Causes of male infertility. In S. J. Parekattil \& A. Agarwal (Eds.). Male infertility (pp.3-14). New York: Springer.

WHO: World Health Organization. (2009). Sexual and reproductive health: Infertility definitions and terminology. Retrieved from http://www.who.int/reproductivehealth/topics/infertility/definitions/en/ 
Table 1. Cross-tabulation analyses and chi-square tests for the number of life events during childhood, and differences in stress levels between infertile and presumably fertile men and women.

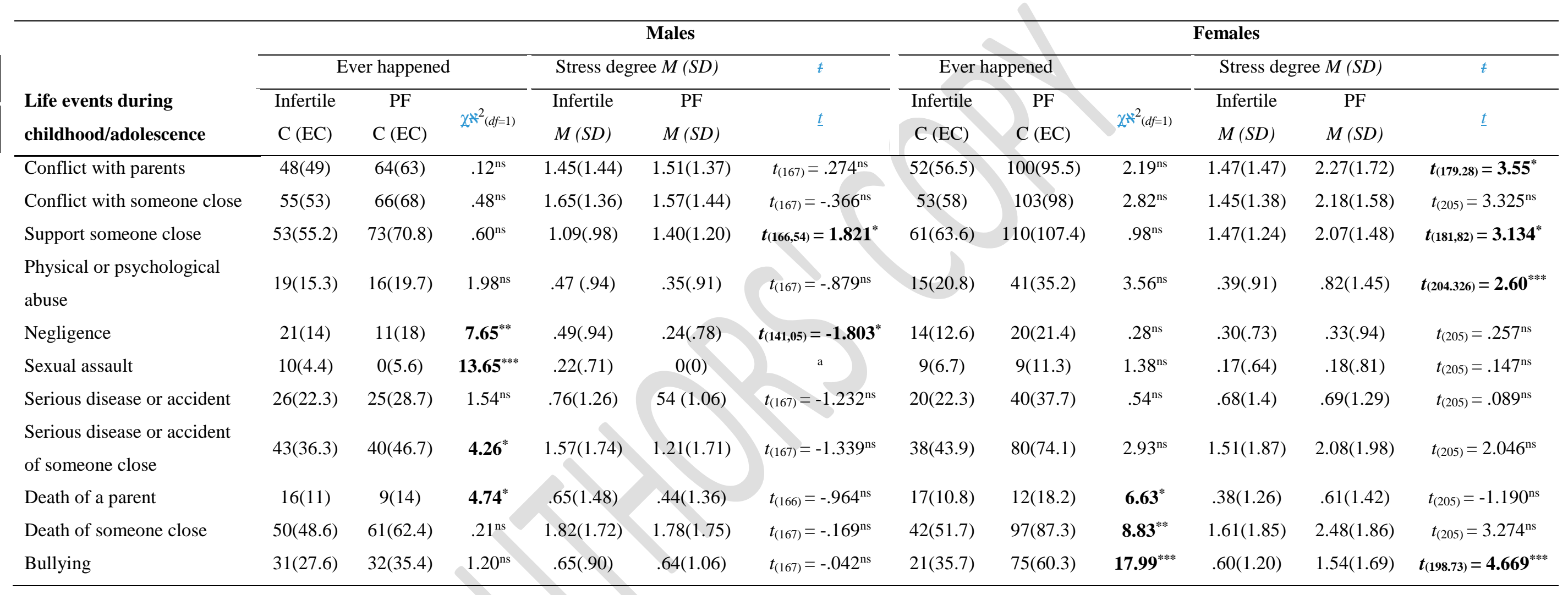

Note. C - Count; EC - Expected count; $\mathrm{PF}$ - presumably fertile; a) differences not analyzed because the PF group did not report any occurrence. ns $p \geq .05, * p<.05, * * p<.005, * * * p<.001$ 
Table 2. Cross-tabulation analyses and chi-square tests for the number of life events during adulthood, and differences in stress levels between infertile and presumably fertile men and women.

\begin{tabular}{|c|c|c|c|c|c|c|c|c|c|c|c|c|}
\hline \multirow[b]{3}{*}{$\begin{array}{l}\text { Life events during } \\
\text { adulthood }\end{array}$} & \multicolumn{6}{|c|}{ Males } & \multicolumn{6}{|c|}{ Females } \\
\hline & \multicolumn{3}{|c|}{ Ever happened } & \multicolumn{2}{|c|}{ Stress degree $M(S D)$} & \multirow[t]{2}{*}{ 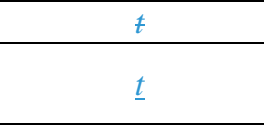 } & \multicolumn{2}{|c|}{ Ever happened } & \multicolumn{3}{|c|}{ Stress degree $M(S D)$} & \multirow{2}{*}{$\underline{t}$} \\
\hline & $\begin{array}{l}\text { Infertile } \\
\mathrm{C}(\mathrm{EC}) \\
\end{array}$ & $\begin{array}{c}\mathrm{PF} \\
\mathrm{C}(\mathrm{EC}) \\
\end{array}$ & $\chi *^{2}(d f=1)$ & $\begin{array}{l}\text { Infertile } \\
M(S D) \\
\end{array}$ & $\begin{array}{c}\mathrm{PF} \\
M(S D) \\
\end{array}$ & & $\begin{array}{l}\text { Infertile } \\
\mathrm{C}(\mathrm{EC}) \\
\end{array}$ & $\begin{array}{c}\mathrm{PF} \\
\mathrm{C}(\mathrm{EC}) \\
\end{array}$ & $\chi *^{2}(d f=1)$ & $\begin{array}{l}\text { Infertile } \\
M(S D) \\
\end{array}$ & $\begin{array}{c}\mathrm{PF} \\
M(S D) \\
\end{array}$ & \\
\hline Conflict with partner & $47(49.9)$ & $67(64.1)$ & $.93^{\mathrm{ns}}$ & $1.28(1.38)$ & $1.46(1.38)$ & $t_{(167)}=.838^{\text {ns }}$ & $43(53.6)$ & $101(90.4)$ & $10.90^{* * * *}$ & $1.12(1.35)$ & $1.95(1.59)$ & $t_{(180.399)}=4.002^{*}$ \\
\hline $\begin{array}{l}\text { Conflict with someone } \\
\text { close }\end{array}$ & $49(48.2)$ & $61(61.8)$ & $.074^{\mathrm{ns}}$ & $1.35(1.33)$ & $1.47(1.42)$ & $t_{(167)}=.571^{\mathrm{ns}}$ & $51(57.7)$ & $104(97.3)$ & $4.87^{*}$ & $1.38(1.31)$ & $2.02(1.50)$ & $t_{(205)}=3.103^{\mathrm{ns}}$ \\
\hline $\begin{array}{l}\text { Support to someone } \\
\text { close }\end{array}$ & $52(52.5)$ & $68(67.5)$ & $.035^{\mathrm{ns}}$ & $.95(.77)$ & $1.42(1.35)$ & $t_{(154,69)}=2.877^{* * *}$ & $53(61)$ & 111(103) & $8.05^{* *}$ & $1.45(1.46)$ & $2.03(1.47)$ & $t_{(205)}=2.738^{\mathrm{ns}}$ \\
\hline $\begin{array}{l}\text { Physical or } \\
\text { psychological abuse }\end{array}$ & $18(10.5)$ & $6(13.5)$ & $11.07^{\text {**** }}$ & $.43(.95)$ & $.12(.50)$ & $t_{(104,29)}=-2.59^{* * *}$ & $10(13)$ & $25(22)$ & $1.34^{\mathrm{ns}}$ & $.21(.70)$ & $.48(1.143)$ & $t_{(204.84)}=2.107^{* * *}$ \\
\hline Sexual assault & $9(3.9)$ & $0(5.1)$ & $12.20^{\text {**** }}$ & $.19(.66)$ & $0(0)$ & & $8(3.7)$ & $2(6.3)$ & $8.24^{* * *}$ & $.16(.63)$ & $.03(.28)$ & $t_{(93.66)}=-1.651^{* * *}$ \\
\hline $\begin{array}{l}\text { Serious disease or } \\
\text { accident. }\end{array}$ & $29(22.6)$ & $25(30.4)$ & $3.17^{\mathrm{ns}}$ & $.95(1.48)$ & $.54(1.13)$ & $t_{(132,92)}=-1.973^{*}$ & $21(20.1)$ & $33(33.9)$ & $.089^{\text {ns }}$ & $.69(1.42)$ & $.77(1.49)$ & $t_{(205)}=.385^{\mathrm{ns}}$ \\
\hline $\begin{array}{l}\text { Serious disease or } \\
\text { accident of someone } \\
\text { close. }\end{array}$ & $41(32.8)$ & $34(42.2)$ & $6.48^{*}$ & $1.46(1.67)$ & $1.07(1.67)$ & $t_{(167)}=-1.485^{\mathrm{ns}}$ & $37(43.1)$ & $79(72.9)$ & $3.18^{\mathrm{ns}}$ & $1.55(2.02)$ & $2.12(2)$ & $t_{(205)}=1.997^{\mathrm{ns}}$ \\
\hline Death of a parent & $23(15.8)$ & $13(20.2)$ & $7.51^{*}$ & $1.04(1.82)$ & $.57(1.50)$ & $t_{(139,954)}=-1.802^{*}$ & $18(10.4)$ & $10(17.6)$ & $10.17^{\text {**** }}$ & $.68(1.50)$ & $.32(1.17)$ & $t_{(130,53)}=-1.806^{* *}$ \\
\hline Death of someone close & $4(45.1)$ & $59(57.9)$ & $.12^{\mathrm{ns}}$ & $1.42(1.54)$ & $1.68(1.76)$ & $t_{(167)}=1.026^{\mathrm{ns}}$ & $44(48.7)$ & $87(82.3)$ & & $1.73(1.93)$ & $2.23(1.92)$ & $t_{(205)}=1.818^{\mathrm{ns}}$ \\
\hline Bullying & $23(18.4)$ & $19(23.6)$ & $2.74^{\mathrm{ns}}$ & $.49(.90)$ & $.28(.66)$ & $t_{(130,261)}=-1.627^{*}$ & $15(21.6)$ & $43(36.4)$ & $4.43^{*}$ & $.35(.84)$ & $.76(1.30)$ & $t_{(203,40)}=2.762^{* * *}$ \\
\hline $\begin{array}{l}\text { Home } \\
\text { change/improvements }\end{array}$ & $58(56)$ & $70(72)$ & $.50^{\mathrm{ns}}$ & $1.50(1.25)$ & $1.35(1.20)$ & $t_{(167)}=-.805^{\mathrm{ns}}$ & $59(61.4)$ & 106(103.6) & $.72^{\mathrm{ns}}$ & $1.45(1.29)$ & $1.81(1.41)$ & $t_{(205)}=1.796^{\mathrm{ns}}$ \\
\hline Conflicts at the work & $59(56)$ & $69(72)$ & $1.14^{\mathrm{ns}}$ & $1.76(1.37)$ & $1.78(1.57)$ & $t_{(167)}=.096^{\mathrm{ns}}$ & $56(58.8)$ & 102(99.2) & $.88^{\mathrm{ns}}$ & $1.86(1.55)$ & $2.26(1.65)$ & $t_{(205)}=1.742^{\mathrm{ns}}$ \\
\hline $\begin{array}{l}\text { Lack of control of work } \\
\text { situation }\end{array}$ & $41(39)$ & $48(50)$ & $.40^{\text {ns }}$ & $1.11(1.33)$ & $1.23(1.46)$ & $t_{(162,711)}=.575^{*}$ & $40(43.1)$ & $76(72.9)$ & $.83^{\mathrm{ns}}$ & $1.19(1.42)$ & $1.82(1.86)$ & $t_{(191,74)}=2.698^{* * *}$ \\
\hline Financial problems & $46(44.2)$ & $55(56.8)$ & $3.15^{\mathrm{ns}}$ & $1.11(1.13)$ & $1.34(1.44)$ & $t_{(166,99)}=1.157^{* *}$ & $42(50.2)$ & $193(84.8)$ & $6.16^{*}$ & $1.12(1.35)$ & $2.02(1.74)$ & $t_{(190,61)}=4.152^{* * *}$ \\
\hline $\begin{array}{l}\text { Change of employment } \\
\text { status }\end{array}$ & $54(52.5)$ & $66(67.5)$ & $.25^{\mathrm{ns}}$ & $1.27(1.09)$ & $1.53(1.47)$ & $t_{(166,672)}=1.303^{*}$ & $53(58.4)$ & 104(98.6) & $3.29^{\mathrm{ns}}$ & $1.43(1.31)$ & $2.36(1.73)$ & $t_{(192,45)}=4.385^{* * *}$ \\
\hline $\begin{array}{l}\text { Partner's change of } \\
\text { employment status }\end{array}$ & $39(36.8)$ & $45(47.2)$ & $.47^{\mathrm{ns}}$ & $.92(1.10)$ & $.97(1.28)$ & $t_{(167)}=.266^{\mathrm{ns}}$ & $41(46.1)$ & $83(77.9)$ & $2.26^{\mathrm{ns}}$ & $1.09(1.32)$ & $1.58(1.61)$ & $t_{(184,419)}=2.395^{* *}$ \\
\hline Sexual difficulties & $23(19.7)$ & $22(25.3)$ & $1.34^{\mathrm{ns}}$ & $.61(1.10)$ & $.39(.88)$ & $t_{(137.646)}=-1.401^{*}$ & $27(33.1)$ & $62(55.9)$ & $3.15^{\mathrm{ns}}$ & $.60(1.01)$ & $1.04(1.39)$ & $t_{(196,221)}=2.618^{* *}$ \\
\hline Problems with family & $41(40.7)$ & $52(52.3)$ & $.008^{\mathrm{ns}}$ & $1.26(1.45)$ & $1.06(1.23)$ & $t_{(167)}=-.938^{\mathrm{ns}}$ & $41(44.6)$ & $79(75.4)$ & $1.12^{\mathrm{ns}}$ & $1.18(1.43)$ & $1.68(1.70)$ & $t_{(181,469)}=2.242^{* *}$ \\
\hline $\begin{array}{l}\text { Problems with partner's } \\
\text { family }\end{array}$ & $29(27.1)$ & $33(34.9)$ & $.355^{\mathrm{ns}}$ & $.73(1.17)$ & $.66(1.09)$ & $t_{(167)}=-.378^{\mathrm{ns}}$ & $38(36.1)$ & $59(60.6)$ & $.31^{\mathrm{ns}}$ & $1.04(1.34)$ & $1.08(1.44)$ & $t_{(205)}=.226^{\mathrm{ns}}$ \\
\hline
\end{tabular}

Note. C - Count; EC - Expected count; $\mathrm{PF}$ - presumably fertile; a) differences not analyzed because the PF group did not report any occurrence. ns $p \geq .05, * p<.05, * * p<.005, * * * p<.00$ 
Table 3. Hierarchical multiple logistic Ordinary least squares regressions predicting male and female infertility.

\begin{tabular}{|c|c|c|c|c|c|c|c|c|c|c|c|c|c|c|}
\hline \multirow[b]{2}{*}{ Predictor } & \multicolumn{7}{|c|}{ Regression predicting infertility diagnosis with male factor } & \multicolumn{7}{|c|}{ Regression predicting infertility diagnosis with female factor } \\
\hline & B & S.E. & Wald $\chi^{2}$ & $d f$ & p-value & Odds Ratio & $\begin{array}{c}\text { 95\% C.I. } \\
\text { Odds Ratio }\end{array}$ & B & S.E. & Wald $\chi^{2}$ & $d f$ & $\begin{array}{c}\mathrm{p}- \\
\text { value }\end{array}$ & $\begin{array}{l}\text { Odds } \\
\text { Ratio }\end{array}$ & $\begin{array}{l}\text { 95\% C.I. } \\
\text { Odds Ratio }\end{array}$ \\
\hline Age & .092 & .031 & 8.784 & 1 & .003 & 1.096 & $1.032 / 1.165$ & .089 & .029 & 9.484 & 1 & .002 & 1.093 & $1.033 / 1.156$ \\
\hline $\begin{array}{l}\text { Stress in } \\
\text { childhood }\end{array}$ & .534 & .377 & 2.001 & 1 & .157 & 1.705 & $.814 / 3.571$ & -.449 & .322 & 1.942 & 1 & .163 & 638 & $.339 / 1.200$ \\
\hline $\begin{array}{l}\text { Stress in } \\
\text { adulthood }\end{array}$ & -.520 & .378 & 1.894 & 1 & .169 & .594 & $.283 / 1.247$ & -.336 & .299 & 1.261 & 1 & .261 & .715 & $.398 / 1.284$ \\
\hline Constant & -3.170 & 988 & 10.283 & 1 & .001 & .001 & - & -2.365 & .935 & 6.396 & 1 & .011 & .094 & - \\
\hline
\end{tabular}

